\title{
Word categorization as a function of stimulus presentation
}

\author{
Kastoor Bhana and Charity O'Neil \\ Departments of Psychology, University of Durban-Westville, Durban, South Africa and University of \\ Oklahoma, USA
}

\begin{abstract}
Word categorization as a function of stimulus presentation was examined by means of the Word Categorization Test, in a group of young adults. The results indicate (a) a minimal use of the phonetic similarity criterion, (b) a differential employment of semantic similarity and complementarity criteria depending upon the stimulus presentation procedure, (c) a significant sex difference, and (d) evidence of response patterning in one of the presentation conditions. The results are discussed in terms of their theoretical and methodological implications.

S. Afr. J. Psychol. 1979, 9: 81-83
\end{abstract}

Woordkategorisering as 'n funksie van stimulusaanbieding is by ' $n$ groep jong volwassenes ondersoek met behulp van die 'Word Categorization Test' (WCT). Die resultate dui op (a) 'n minimale gebruik van die fonetiese soortgelykheidskriterium, (b) afhangende van die wyse van stimulusaanbieding, die differensiële gebruikmaking van die semantiese soortgelykheidskriterium en die komplementariteitskriterium, (c) 'n beduidende geslagsverskil, en (d) aanduidings van responspatroonvorming by een van die stimulusaanbiedingswyses. Die resultate word bespreek in terme van hulle teoretiese en metodologiese implikasies.

S.-Afr. Tydskr. Sielk. 1979, 9: 81-83
There has been some very suggestive research into how individuals organize their environmental input into meaningful patterns. Several dimensions of organization, for example, relational, inferential have been proposed.

Denney (1974a) came to the conclusion that all the dimensions suggested could perhaps be reduced to two, namely complementarity and similarity. Complementarity refers to the organization of stimulus input in terms of some shared interrelationships where stimuli that go with each other in some way, or act upon each other, are grouped together, e.g. water and faucet. A similarity criterion refers to organization on the basis of some shared perceptual or functional similarity, e.g. tap and faucet.

The published research has generally employed actual objects or pictures of objects and occasionally words as stimuli. A developmental shift occuring between ages five to 10 where the categorization criterion is presumed to change from predominant complementarity to similarity basis has also been reported.

Bhana (1976) working with the Word Categorization Test (WCT) indicated some cross-cultural generality for the reported literature. Briefly, the WCT consists of three lists of 20 word triads: list 1 can be grouped only in terms of phonetic or semantic similarity, e.g. hop, jump, cop; list 2 in terms of phonetic and complementarity criteria, for example, milk, silk, cat; and list 3 in terms of complementarity or semantic similarity, e.g. infant, stroller, baby.

A notable finding of this research was the almost total absence of the use of the phonetic categorization criterion. It was felt that this could be attributed to the mode of stimulus presentation. The subjects read the words themselves but did not hear them. It is reasonable to assume that listening to the WCT might influence the use of the phonetic categorization criterion. Thus important information may be obtained by varying stimulus presentation.

Bhana (1976) in keeping with the other workers in the area, employed a forced choice procedure. Each word triad could only be categorized in two ways. Perhaps if the imposed structure of the WCT was removed different results may be obtained. This further influenced the 
design of this study.

Another motivating factor was the desire to check the usefulness of the WCT for research in this area. The WCT had already demonstrated its usefulness with children aged 10 to 14 (Bhana 1976). In view of the evidence suggestive of regression towards an earlier categorization mode for senior adults (Denney 1974b), it might be beneficial to check the usefulness of the WCT across the life span. Thus the subjects of this research were not youths but young adults. It is hoped to extend the research to senior adults at a future date.

In summary, this research was designed to examine further the word categorization criteria as a function of stimulus presentation in a group of young adults.

\section{Method}

\section{Subjects}

Three hundred subjects, (mean age 18,3 years) divided randomly into three groups of 100 each, participated. There were 50 men and 50 women in each group. The subjects were drawn from the introductory psychology class of the University of Oklahoma.

\section{Procedure}

The basic stimulus material was the WCT. A group testing procedure was employed.

The subjects comprising group 1 (the visual condition) were given the WCT with the instruction that they were to circle or underline any two words of a triad that went together or were alike in some way. No other instructions were given.

The procedure was essentially the same for group 2 (the auditory condition subjects). They listened to the instructions and the WCT stimuli from a pre-recorded tape. They heard each word triad after which they had five seconds to write down the two words that went together in some way, on the provided response sheets.

For group 3 (the visual-free condition subjects) the format of the WCT was altered. All the words comprising the list 3 triads (list 3 could be grouped only according to complementarity or similarity criteria) were presented in paragraph form in a scrambled order. On the next page was a list of 20 words, each word a part of a single word triad of list 3 , arranged one below the other. The subjects were required to write down for each listed word, a word from the first sheet that went with it in some way. Thus the subjects had to search for the grouping word.

\section{Results}

For each group the response measure was the criterion, phonetic, semantic similarity or complementarity, employed for grouping the word triads of the WCT. Mean usuage of each criterion for every list was calculated for each group.

Group 1 (the visual condition subjects) used the phonetic criterion an average of 0,86 times for list 1 , and 1,65 times for list 2 . The results were similar for group 2 (the auditory condition subjects) who scored means of 0,58 for list 1 and 0,72 for list 2 . The maximum possible score for each list would be 20 . Thus in spite of hearing the word triads, phonetic categorization was used minimally, a finding supporting theoprexieusseresearch
(Bhana 1976).

In view of this, lists 1 and 2 which involved the phonetic criterion were not utilized in further analyses. Attention was focussed rather on list 3 which could only be categorized on the semantic or complementarity criteria.

A general trend in responses on the third list was the greater usage of the semantic similarity criterion than the complementarity criterion, but the mode of stimulus presentation appeared to influence this.

A $2 \times 3$, sex $\times$ presentation mode, analysis of variance with the difference scores (semantic - complementarity criteria) as the dependent measure was calculated. The findings were a significant sex effect, $\underline{p}<0,05$, with the men grouping more on semantic similarity than the women, and a significant mode of presentation effect, $\underline{p}<0,001$.

This highly significant overall $\underline{F}$-test on the main effect suggested that one or all of the possible comparisons on this latter factor could be significant. This was tested by the posteriori test developed by Tukey and referred to as the Tukey (a) procedure (also known as the honestly significant difference (HSD) procedure) (cf Winer (1962) for theoretical and statistical issues involved). This test revealed that each presentation condition was significantly different from the other (HSDq, 01,294 =2,95), that is, the visual and auditory conditions were significantly different from each other as were the visual and visualfree and the auditory and visual-free comparisons. The means for the three presentation conditions were 10,57 (group 1, the visual condition), 13,64 (group 2, the auditory condition) and 7,07 (group 3 , the visual-free condition).

A closer examination of the responses on list 3 raised the possibility of some kind of response patterning. Subjects appeared to be employing more complementarity groupings initially and then switching to semantic similarity groupings. To check this statistically a difference score between the number of complementarity groupings in the first 10 and the second 10 triads was computed for each subject of all the groups.

A $2 \times 3$ (sex $\times$ presentation mode) analysis of variance, using the obtained difference scores as the dependent variable, was computed. Only the main effects of sex and presentation mode were significant (sex, p < 0,05 ; presentation mode, $\underline{p}<0,001$ ). The female subjects tended to switch strategies to a greater extent than the male subjects, and this was particularly so for the group 1 subjects.

The means for the three presentation conditions were 2,98 for group 1, 1,46 for group 2 and 1,39 for group 3 . The Tukey (a) test revealed that the significant main effect of presentation mode was due to differences between groups 1 and 2, and 1 and 3 (HSDq, 01,294 = 0,95; HSDq, $05,294=0,76$ ). This finding suggests that there was greater strategy switching in the visual condition than in the other conditions.

\section{Discussion}

The usefulness of the WCT to examine conceptual categorization is supported. The WCT can be used sucоксеssfully:madithaolderindividuals to answer some pertinent 
questions on cognitive organization throughout the lifespan.

During the early childhood period we usually find a heavy emphasis on words that go together phonetically. The traditional nursery rhymes are a good example. However, by the time the child reaches 10 years phonetic similarities are not utilized as much. All the subjects in Bhana (1976) and in this study made almost negligible use of this criterion. Whether this represents a developmental shift is difficult to answer. It could simply be a reflection of what is necessary, and thus developed and nurtured, for functioning in a formal school situation. We cannot say whether the employment of phonetic similarity represents a 'lower-level' of information processing.

Apart from phonetic similarity, the significance of the use of semantic or complementarity criteria is difficult to determine. There is no doubt that children and young adults use semantic similarity more than complementarity.

According to Denney (1974a) the former involves greater abstraction and thus perhaps a more complex level of functioning. The finding that the relative employment of these criteria is influenced by the presentation procedure should caution one against making such generalizations. It appears that children, certainly from age 10 onwards, are capable of employing both criteria and their relative use could simply be a function of experimental and environmental demands.

This study also has methodological implications. Previous research has employed the presentation mode analogous to the visual condition of this study. Signifi- cant response patterning was found in this condition. This needs to be further examined. A more useful method appears to be the visual-free condition. This would give only indications of preference and not capability. Interpretations in terms of developmental progressions may be premature at this point.

The significant sex difference finding in the use of particular criteria is also interesting, and would appear to favour the environmental demand interpretation rather than an inherent sex difference in word categorization criterion interpretation.

Important practical issues are also raised. The significant presentation mode effect supports the general finding that information can be processed differently depending upon how it is received. For example any material of equal complexity may be differently processed depending upon whether it is received visually or auditorily, a conclusion which research in the area is already suggesting.

\section{References}

Bhana, K. Concept utilization among Indian subjects, S. Afr. J. Psychol. 1976, 6, 57-62.

Denney, N.W. Evidence for developmental changes in categorization criteria for children and adults. Hum. Dev. 1974a, 17, 41-53. $41-53$.

Denney, N.W. Classification abilities in the elderly. J. Geront. 1974b, 29, $309-314$

Winer, B.J. Statistical Principles in Experimental Design. McGraw Hill: New York, 1962 